\title{
An efficient Mppt approach of PV systems: incremental conduction pathway
}

\author{
Murari Lal Azad ${ }^{1}$, Pradip Kumar Sadhu' ${ }^{2}$, P. Arvind ${ }^{3}$, Anagh Gupta ${ }^{4}$, Tuhin Bandyopadhyay, \\ Soumya Das ${ }^{6}$, Sabyasachi Samanta ${ }^{7}$ \\ ${ }^{1,2}$,Departement of Electrical Engineering, Indian Institute of Technology (Indian School of Mines), India \\ 3,4,5,6,7 Departement of Electrical Engineering, UIT, Burdwan University, India
}

\begin{tabular}{l}
\hline Article Info \\
\hline Article history: \\
Received Jan 20, 2019 \\
Revised Mar 10, 2019 \\
Accepted Apr 11, 2019 \\
\hline
\end{tabular}

\section{Keywords:}

AIncremental conduction

BMPPT

CPV

DBoost converter

EPWM inverter

\begin{abstract}
Distributed Generation source have wide application due to their phenomenal advantages. These sources include Photovoltaic (PV) cells producing DC voltage at their output that connects the network through a power electronic interface. PV characteristics, on the other hand, illustrate the fact that maximum power can be extracted at the optimal operating point depending upon the solar radiation and ambient temperature. In order to keep the PV module at its optimal operating point, a DC-DC converter is often used between a PV module and inverter. Consequently, Maximum power point trackers (MPPT) grab the foremost position in the efficiency analysis of the global PV system. Among the several MPPT algorithms, Incremental Conduction technique isemphasised upon as it is extremely simple in implementation within electronic programmable circuits. This paper incorporates the MPPT model using a PV module that always works in its optimal operating point. Design and experimental results of a small prototype of MPPT is presented here based on the Simulink model to verify the advantages of proposed integrated system.
\end{abstract}

Copyright $(2019$ Institute of Advanced Engineering and Science. All rights reserved.

\section{Corresponding Author:}

Soumya Das,

Departement of Electrical Engineering,

University Institute of Technology,

Burdwan University,

Burdwan, West Bengal-713104, India.

Email: Soumya.sd1984@gmail.com

\section{INTRODUCTION}

The immediate measures to switch over to greener energy are being called for by the rapidly diminishing conventional energy resources. We are entirely dependent on the non-renewable energy resources that are posing aserious threat to a sustainable future in the present world. Thus, there is a demand for a clean and green energy in the present scenario [1-6]. Photovoltaic systems, wind turbines and energy storage systems are some of the most popular and widely used renewable energy resources for electricity generation. The most feasible among them is the Solar cell owing to its utility in the various fields of application, both residential and industrial. On account of fewer losses, D.C power is more preferred over A.C. Since photovoltaic systems provide a D.C output, they are more beneficial [7].

A significant portion of today's research in the field of solar energy is being represented by modelling of photovoltaic devices and simulating their behaviour. The photovoltaic devices suffer from few major flaws in spite of being environment friendly. Their efficiency of converting solar energy to electrical energy being their major flaw. There is a complex relationship between the surrounding environment of operation and the maximum power that can be produced in case of photovoltaic cells. The effect of the temperature also has a significant impact on solar PV cells [8]. It can be seen that the cell with the lowest 
temperature produces the highest output power and vice versa. Due If a load is diredtly connected to a solar panel, its operating point will rarely produce peak power and the impedance seen by the panel determines the operating point of it. Therefore, if the impedance seen by the panel is varied, the operating point can be traversed towards the peak.

Considering this disadvantage, an improved approach for employing solar power has been developed in this paper. The maximum power point tracking (MPPT) which is implemented in PV inverters is an algorithm which continuously adjusts the impedance experienced by the solar array for keeping the PV system operating close to the peak power point of the panel under changing conditions of solar irradiation, temperature etc. Maximum Power point tracking through Incremental Conduction algorithm is executed to obtain a more optimized system.

There are several strategies that can be followed for optimizing the power output of an array and MPPT devices can switch between different algorithms on the basis of the operating condition of the array. The P\&O (Perturb and observe) and Incremental conductance are both the examples of "hill climbing"method which are used to find in the operating condition of PV array, the local maximum of power curve for providing a true MPP. The P\&O method suffers from the requirement of oscillating output power even under steady state irradiance around the MPP. The Incremental Conductance method has the advantage of determination of MPP without oscillations around the value unlike the P\&O method and thus can perform MPPT under rapidly varying irradiation conditions with better accuracy on comparison with P\&O. When there is abrupt change in weather conditions, the irradiance changes. On account of this, as the MPP continuously changes, the $\mathrm{P} \& \mathrm{O}$ method considers it as a change in MPP rather than irradiance due to perturbation ending up calculating the wrong MPP in some cases. The developed model works at a higher efficiency and can also serve as base model for implementation of other MPPT techniques. A joint simulation of the photoelectric device with power electronics interfaces can be performed by using an equivalent circuit for its modeling [9-13]. The system was optimized before practical application using these simulations, thus, being cost effective. The standard of a good PV Generator is its efficiency which can be carried out if it constantly converts the maximum of the available solar power all the time. Thus, it can be statedthat the maximum power delivered should always be in co-ordination with the prevailing conditions, i.e., temperature, irradiance, wind speed (for windmills) for keeping the MPP [maximum power point] at its global maximum [14]. A voltage converter associated with an electronic maximum power point tracking (MPPT) system are used for accomplishing maximum power production [15-18]. Testing and execution of the MPPT technique which is based on the Incremental Conduction method is performed by the Simulink model as well as a small prototype model.

\section{RESEARCH METHOD}

The desired power output is obtained by joining several PV cells together. The proposed model of a photovoltaic generator, supplying a DC load through an adaptation stage, composed by a boost converter driven by an MPPT technique assuming the maximum efficiency for the energy transfer is constituted in the physical model of the process under inspection. The schematic arrangement of the model is displayed in Figure 1. A simulated model of the real process in agreement with the physical model has been developed using simulink to improve the efficiency.

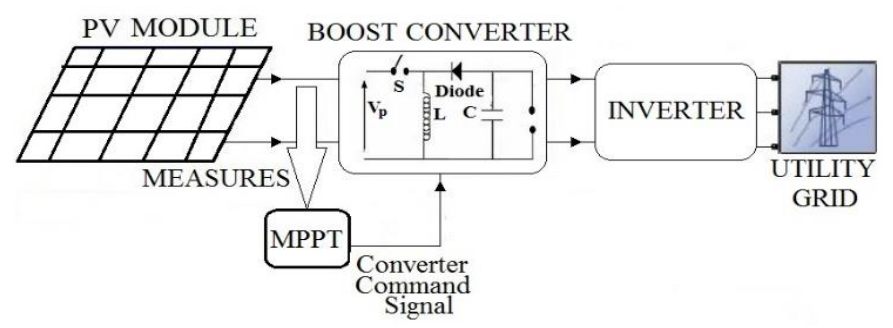

Figure 1. Schematic diagram of grid-connected solar PV with MPPT.

\subsection{Mathematical Model of Solar Cell}

For analysis of mathematical representation, a basic single-diode model is chosen [19]. The PV cells are connected in series to obtain the desired power output. Figure 2 shows a simplified model of the solar cell. 


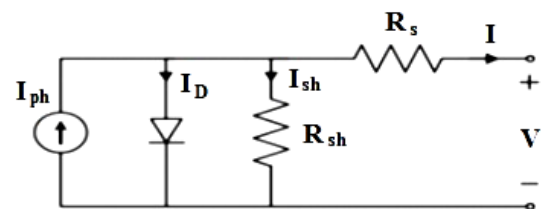

Figure 2. Simplified equivalent circuit of a PV Cell

Where $I_{p h}=$ photon generated current

The following equation describes the mathematical modelling of photovoltaic array:

$$
I=N_{p} I_{p h}-N_{p} I_{d}\left(e^{\left(\frac{q V_{p v}}{k T A N_{s}}\right)}-1\right)
$$

Where, the number of cells connected in series and parallel are $N_{s}$ and $N_{p}$ as used in the PV module to achieve the desired output. $R_{s}$ and $R_{p}$ are the intrinsic parallel and series resistances associated with the panel. Deviation of the characteristics of an ideal p-n junction is evaluated by the actualization factor denoted by 'A'. $K$ and $q$ represent Boltzmann constant and charge on an electron respectively.

The photon generated current $I_{p h}$ depends on temperature and solar irradiance.

$$
\begin{aligned}
& I_{p h}=\left[I_{s c r}+K I\left(T_{o p}-T_{r e f}\right)\right] \frac{S}{100} \\
& I_{p h}=\left[I_{s c r}+K I\left(T_{o p}-T_{r e f}\right)\right] I_{r r}
\end{aligned}
$$

The diode reverse saturation current is denoted by $I_{d}$ and it varies with temperature based on the equation between solar panel current and voltage as followed:

$$
I_{d}=I_{r r}\left[\frac{T}{T_{r}}\right]^{3} \exp \left(\frac{q E_{g}}{k A}\left[\frac{1}{T_{r}}-\frac{1}{T}\right]\right)
$$

In the above expression, the energy gap of the semiconductor is denoted by $E_{g}$.

$$
E_{g}=E_{g}(0)-\frac{\alpha T^{2}}{\beta+T}
$$

The final output power is given by the product of load current and thermal voltage which is in turn given by the following equation:

$$
P=V I=N_{p} I_{p h}\left[\frac{q V}{k T A N_{s}}-1\right]
$$

If $I_{s h}$ is considered to be the shunt current then,

$$
I_{s h}=\left(V+I R_{s}\right) / R_{p}
$$

$I$ being the load current.

$I=\left(I_{p h} N_{p}-\left(I_{s h}+I_{d}\right)\right)$ 
Where, $N_{p}$ is the number of cells connected in parallel.

$V$ being the output voltage across the load, and $I$, the load current.

\subsection{Incremental Conduction MPPT Algorithm}

Incrementally comparing the ratio of the derivative of conductance with the instantaneous conductance is the idea behind IC. It is derived from the fact that at MPP, the derivative of power with respect to voltage $(\mathrm{d} P / \mathrm{d} V)$ is in fact zero, i.e. [20].

$$
\frac{\mathrm{d} P_{P G}}{\mathrm{~d} V_{P G}}=\frac{\mathrm{d}\left(V_{P G} I_{P G}\right)}{\mathrm{d} V_{P G}}=I_{P G}+V_{P G} \frac{\mathrm{d} I_{P G}}{\mathrm{~d} V_{P G}}=0
$$

As shown in (9) can be rearranged in the following form:

$$
-\frac{I_{P G}}{V_{P G}}=\frac{\mathrm{d} I_{P G}}{\mathrm{~d} V_{P G}}
$$

Where, $\mathrm{d} I_{P G}$ and $\mathrm{d} V_{P G}$ are the increments of PV current and voltage, respectively. The basic rules for IC can thus be derived from the $\mathrm{P}-\mathrm{V}$ characteristics can be written as:

$$
\left\{\begin{array}{l}
\frac{\mathrm{d} I_{P G}}{\mathrm{~d} V_{P G}}=-\frac{I_{P G}}{V_{P G}}, \text { At MPP } \\
\frac{\mathrm{d} I_{P G}}{\mathrm{~d} V_{P G}}>-\frac{I_{P G}}{V_{P G}}, \text { Left of MPP } \\
\frac{\mathrm{d} I_{P G}}{\mathrm{~d} V_{P G}}<-\frac{I_{P G}}{V_{P G}}, \text { Right of MPP }
\end{array}\right.
$$

Using the rules in (11), the basic flow chart for IC is depicted in Figure 3.

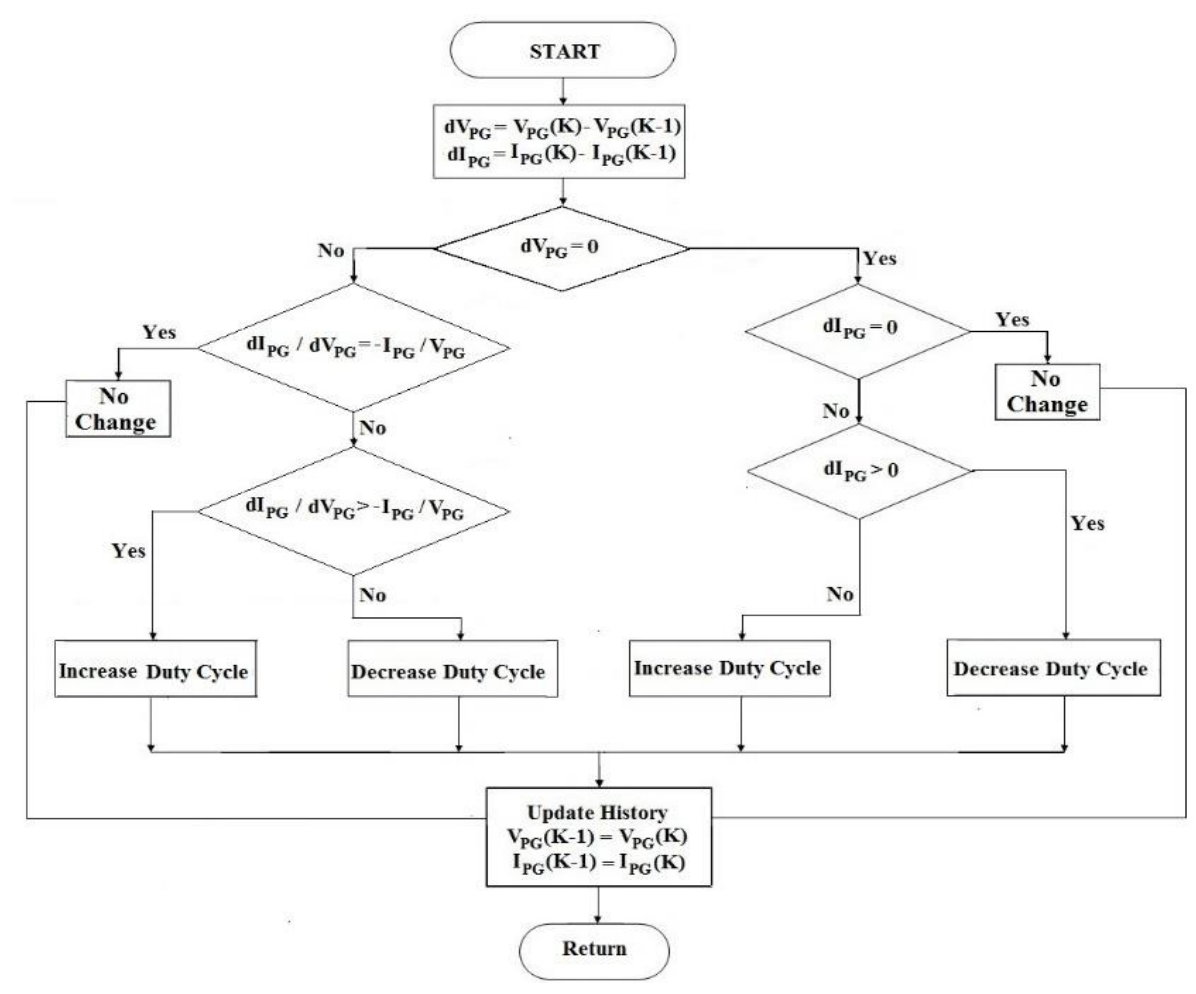

Figure 3. Incremental conduction algorithm flow chart 


\section{RESULTS AND ANALYSIS}

A sample system has been simulated by MALAB/Simulink in order to illustrate and verify the advantages underlying the proposed integrated system. In this context, by varying the solar radiation and maintaining constant temperature, the proposed system has the ability to extract maximum power from PV. The proposed model utilizes the output from the PV panel and is followed by the implementation of MPPT tracking into the system. By means of incremental conductance algorithm the maximum global efficiency is attained with the help of these trackers. Besides, the dc voltage obtained is converted into 3 phase ac voltage using an inverter. For controlling the output, a PWM inverter is incorporated into the system. The graphs displaying the Maximum output power, voltage versus the variation of duty cycle and irradiance are shown in Figure 4 a, b, c, d respectively. Nevertheless, at constant temperature condition, the variation of solar radiation has been considered. Assume that temperature is $25^{\circ} \mathrm{C}$ and solar radiation varies from 1000 to $250 \mathrm{~W} / \mathrm{m}^{2}$.
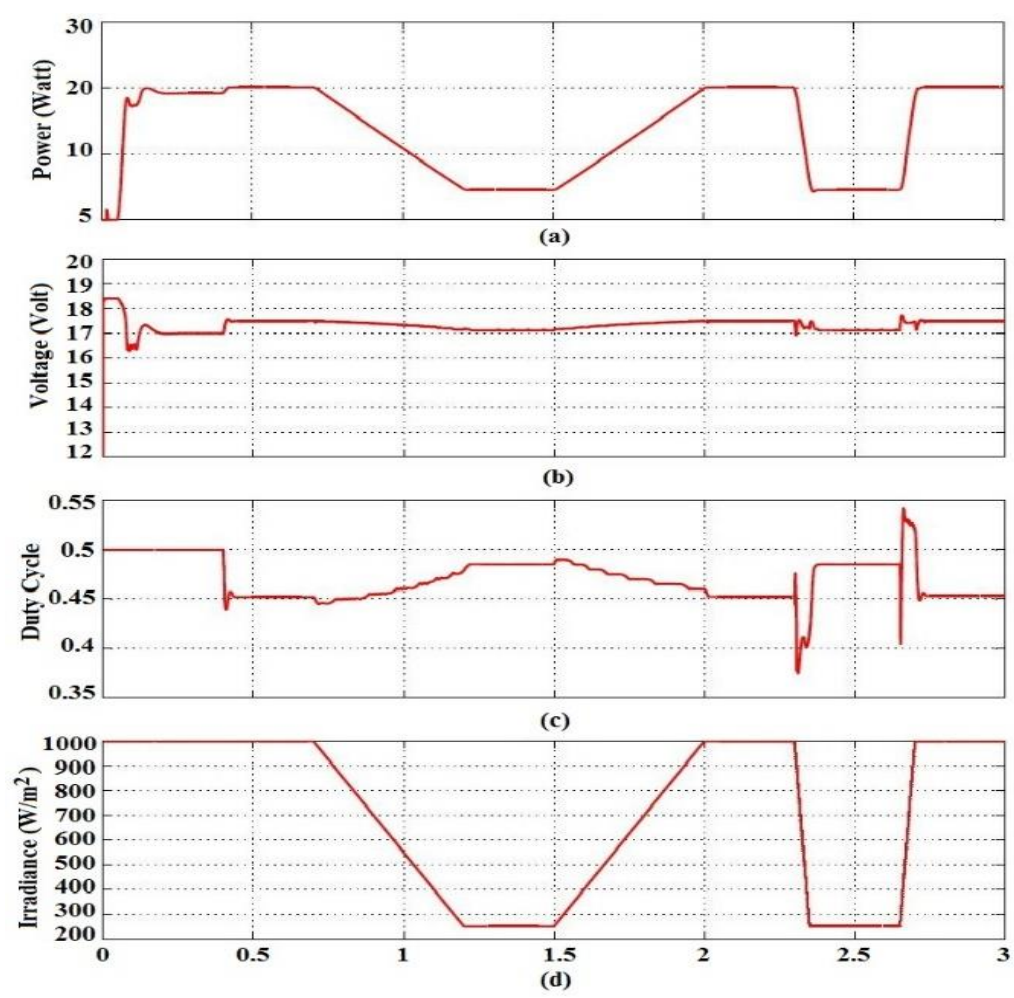

Figure 4. (a) Generated power of PV in varying solar radiation, (b) Generated voltage of PV in varying solar radiation, (c) variation of Duty Cycle, (d) variation of solar radiation

The irradiance experienced by the solar panel changes depending on the time of the day and in in this case it is maintained at $1000 \mathrm{~W} / \mathrm{m}^{2}$ in the interval of 0 to 0.75 and then switches through an interval of 0.75 to 1.20 to $250 \mathrm{~W} / \mathrm{m}^{2}$ and is maintained there upto 1.5 . Depending on the change in the solar irradiance, the program varies the duty cycle of the Boost converter so that the voltage output can be maintained within a particular range of around 16 to 18 volts. For irradiation on the solar panel has its impact on the output voltage. From Figure 4 it can be distinctly observed that there is an increase in output voltage with increase in the irradiation. The simulation results and the results obtained from the hardware implementation are found to be in close proximity.

For extracting the maximum power point the voltage is tracked by trackers utilizing incremental conductance. The MPP is efficiently trackedby this algorithm which can be verified from the obtained results.

A DC-DC boost converter is used to step up th voltage to the desired value and Figure 5 demonstrates the boost-voltage profile depicting the final output voltage that is optimized using trackers. The output of the boost converter is having a fixed voltage level and it is then fed to a PWM inverter for converting DC power to 3 phase AC power. 


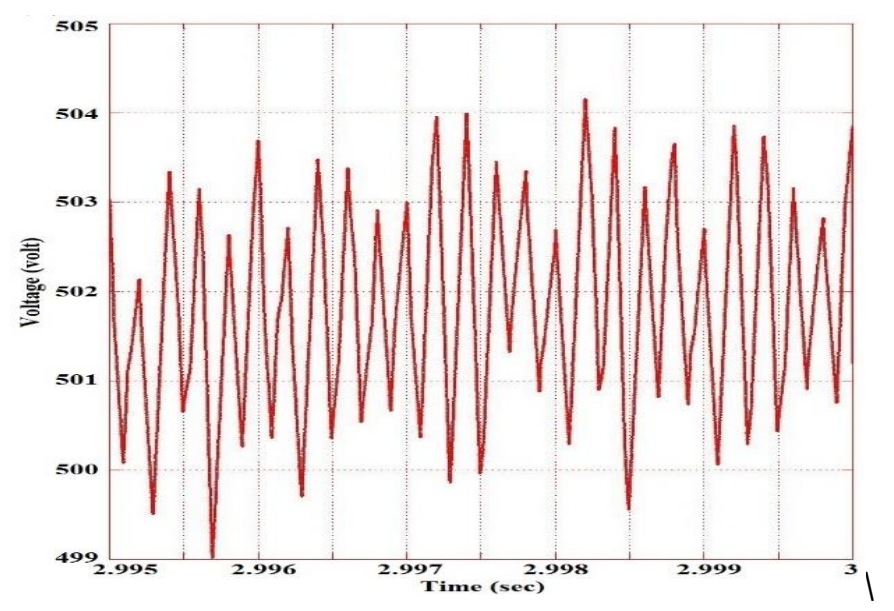

Figure 5. Output voltage of boost converter

For obtaining the desired results, a pulse width modulation has been utilized in both the simulation as well as in the prototype. The simulation result of the PWM is illustrated in Figure 6.

For converting the obtained dc voltage to ac voltage, PWM inverter has been incorporated. The Figure 7 illustrates the sinusoidal wave obtained from the inverter. Red, blue and green colours are used to depict the three phases respectively. The voltages generated are in phase with each other.

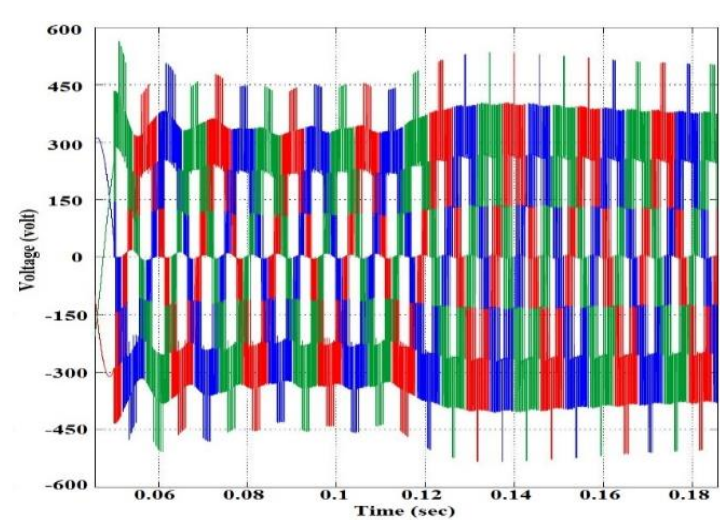

Figure 6. Output voltage of PWM

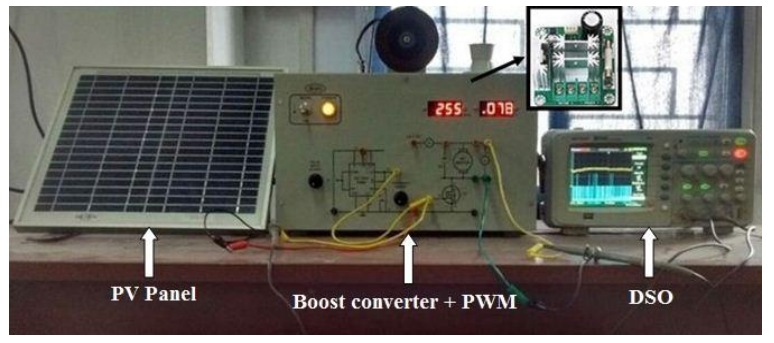

Figure 7. Experimental set up of PV with MPPT (IC) Technique

\section{CONCLUSION}

Theestablishment of a proposed simulation model as well as a small hardware model for the solar photovoltaic system performed along with Incremental Conduction technique for Maximum Power Point Tracking is being primarily presented by this paper. The development of an efficient and optimized system is the aim of this paper. The load of the maximum power point tracker has to match its load to that of the maximum available power from a PV generator (PVG) providing the highest global electrical efficiency. This was achieved by the integration of Incremental Conduction algorithms into the MPPT controller. The Aforesaid algorithm is used to control the duty cycle of the boost converter. The prototype model efficiently tracks the maximum power point. The common method is implemented under MATLAB/Simulink environment. The intensity of sunlight may reach up to $1000 \mathrm{~W} / \mathrm{m}^{2}$ in many countries located in the tropical and temperate belt. From simulated characteristics, the impact of irradiance variations at constant temperature could also be observed. The PV array output is stepped up by using the boost converter with the Incremental Conduction technique for controlling the duty ratio of boost converter switch. Future scope involves the development of stand-alone grid fed systems which can perform independently. The primary goal of simulating the proposed system and the development of proposed model prototype has been achieved. 


\section{REFERENCES}

[1] S Salisu, M. W. Mustafa, M Mustapha, "A Wavelet Based Solar Radiation Prediction in Nigeria Using Adaptive Neuro-Fuzzy Approach," Indonesian Journal of Electrical Engineering and Computer Science (IJEECS), vol.12,pp.907-915, 2018.

[2] N. I. Zolkifri, C. K. Gan, M Shamsiri, "Performance analysis of Malaysian low voltage distribution network under different solar variability days," Indonesian Journal of Electrical Engineering and Computer Science (IJEECS), vol.13, pp1152-1160, 2019.

[3] E. Roslan, I. Hassim, "Solar PV system with pulsating heat pipe cooling," Indonesian Journal of Electrical Engineering and Computer Science (IJEECS), vol.14,pp.311-318, 2019.

[4] S.Das, P K.Sadhu, S.Chakraborty, N.Pal, G.Majumdar, "New Generation Solar PV Powered Sailing Boat Using Boost Chopper," TELKOMNIKA (Telecommunication Computing Electronics and Control) Indones. J. Electr. Eng, vol.12,pp. 8077-8084,2014.

[5] S Das., P K Sadhu., N.Pal, S.Mukherjee, "Single Axis Automatic Solar Tracking System Using Micro-controller," TELKOMNIKA (Telecommunication Computing Electronics and Control) Indones. J. Electr. Eng, vol.12, pp.80288032, 2014.

[6] M L Azad., P K Sadhu., S. Das, B. Satpati., A.Gupta, P.Arvind, R. Biswas, “An Improved Approachto Design a Photovoltaic Panel," Indonesian Journal of Electrical Engineering and Computer Science (IJEECS), vol.5,pp.515520, 2017.

[7] K. Shenai., K.Shah, "Smart DC Micro-grid for Efficient Utilization of Distributed Renewable Energy," Digest of IEEE Applied Power Electronics Conference and Exposition, 2011.

[8] S. Chander, A. Purohit, A. Sharma, S. P. Nehra, and M. S. Dhaka, "Impact of temperature on performance of series and parallel connected mono-crystalline silicon solar cells," Energy Reports, vol. 1, pp. 175-180, 2015.

[9] Y. Li, W. Huang, H. Huang, C. Hewitt, Y. Chen, G. Fang, et al., "Evaluation of methods to extract parameters from current-voltage characteristics of solar cells," Sol Energy,vol. 90, pp.51-7,2013.

[10] P.Maffezzoni, L Codecasa., D'Amore D, "Modeling and simulation of a hybrid photovoltaic module equipped with a heat-recovery system," IEEE Trans Ind Electron, vol.56, pp.4311-4318, 2009.

[11] D.Dondi, A.Bertacchini, D.Brunelli, L Larcher,() "Modeling and optimization of a solar energy harvester system for self-powered wireless sensor networks," IEEE Trans Ind Electron, vol.55, pp.2759-66,2008.

[12] N.D Benavides., PL Chapman, () "Modeling the effect of voltage ripple on the power output of photovoltaic modules," IEEE Trans Ind Electron,vol. 55, pp. 2638-43, 2008

[13] AlHajri,M.F., El-Naggar K.M., AlRashidi M.R., Al-Othman AK, "Optimal extraction of solar cell parameters using pattern search," Renew Energy, vol.44, pp.238-45,2012.

[14] A. Zegaoui, M.Aillerie, P. Petit, Sawicki J P., J P. Charles, A W Belarbi,"Dynamic behaviour of PV generator trackers under irradiation and temperature changes,” Solar Energy, vol.85, pp.2953-2964, 2011.

[15] R D.Tapakis, A G Charalambides, "Performance evaluation of a photovoltaic park in Cyprus using irradiance sensors," Journal of Power Technologies, vol. 94 (4), pp.296-305,2014.

[16] Attou, A. Massoum, M. Chadli, "Comparison study of two tracking methodsfor photovoltaic systems," Rev. Roum. Sci. Techn. - Électrotechn. et Énerg., Bucarest,vol. 60 (2), pp.205-214, 2015.

[17] Bellia A. H.,y.ramdani, F. Moulay, K. Medles, "Irradiance and temperature impact on photovoltaic power by design of experiments," Rev. Roum. Sci. Techn. - Électrotechn. et Énerg., Bucarest,vol. 58(3), pp.284-294, 2013.

[18] S.Das, P K.Sadhu,S.Chakraborty,S.Banerjee, T.Saha, "Design and Implementation of an Intelligent Dual-Axis Automatic Solar Tracking System," Revue Roumaine des Sciences Techniques - Électrotechnique et Énergetique,vol.61(4),pp. 383-387,2016.

[19] R. N. Bharti, R. K Mandal, "Modeling and Simulation of Maximum Power Point Tracking for Solar PV System using Perturb and Observe Algorithm," International Journal of Engineering Research \& Technology, vol.3 (7), 2014.

[20] Kashif Ishaque, Zainal Salam., "A review of maximum power point tracking techniques of PV system for uniform insolation and partial shading condition," Renewable and Sustainable Energy Reviews,vol. 19, pp.475-488, 2013.

\section{BIOGRAPHIES OF AUTHORS}

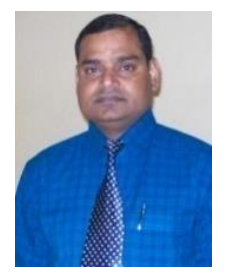

Murari Lal Azad received his Bachelor degree in 1998 from GB Pant University Pant Nagar, US Nagar India and Post-Graduate degree in 2012. Currently, he is working with Amity University, Greater Noida Campus as an Associate Professor in Electrical Engineering Department. He is presently pursuing Ph.D. programme in Electrical Engineering from IIT (ISM), Dhanbad826004, India. 


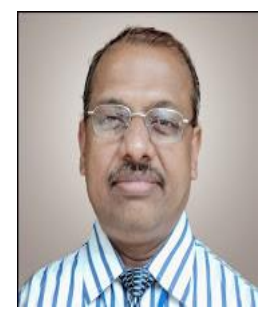

Pradip Kumar Sadhu received his Bachelor, Post-Graduate and Ph.D. (Engineering) degrees in 1997, 1999 and 2002 respectively in Electrical Engg. from Jadavpur University, West Bengal, India. Currently, he is working as a Professor in Electrical Engineering Department of IIT (ISM), Dhanbad, India.

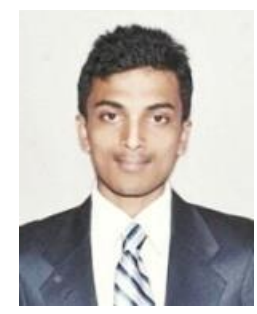

P. Arvind received his Bachelor degree in electrical engineering in 2017 from University Institute of Technology, Burdwan University, West Bengal, India.

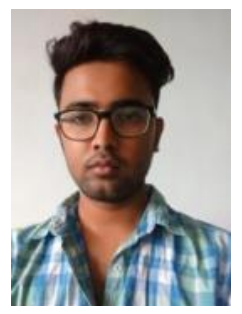

Anagh Gupta received his Bachelor degree in electrical engineering in 2017 from University Institute of Technology, Burdwan University, West Bengal, India.

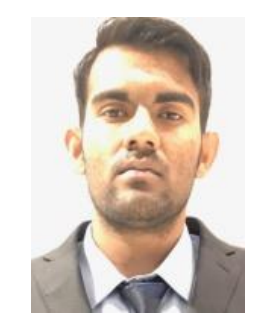

Tuhin Bandyopadhyay will receive his Bachelor's degree in Electrical Engineering by 2019 from University Institute of Technology, Burdwan University, West Bengal, India.. His current areas of interest are solar photovoltaic systems, Mathematical Modelling of Biological Systems.

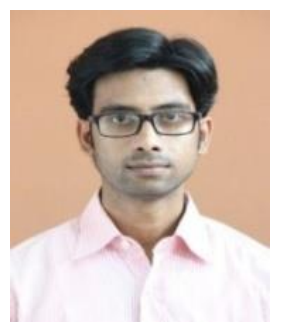

Soumya Das received his Bachelor degree in 2007 from WBUT; He received his Post-Graduate degree in 2010 from Jadavpur University, West Bengal, India.; He received his Ph.D. (Engineering) degree from IIT (ISM) Dhanbad, India. Currently, he is working as an Assistant Professor in Electrical Engineering Department of University Institute of Technology, Burdwan University, India.

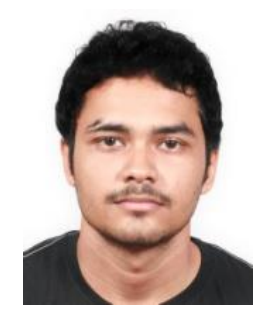

Sabyasachi Samanta received his Bachelor degree in 2014 from University Institute of Technology, Burdwan University(BU); He received his Post-Graduate degree in 2016 from Dr. B.C.Roy Engineering College,Durgapur, MAKAUT, West Bengal, India. Currently, he is working as a Guest Lecturer in Electrical Engineering Department of University Institute of Technology, Burdwan University, India. 